\title{
Study on the Removal of Aniline by Plant Assisting Activated Sludge
}

\author{
Yan $\mathrm{Li}^{1,}$ a , Wenqiang Jiang ${ }^{2, \mathrm{~b}}$, Bo Wang ${ }^{3, \mathrm{c}}$ \\ ${ }^{1,2}$ School of Environmental Science and Engineering, \\ Qilu University of Technology, Jinan 250353, China; \\ ${ }^{3}$ Shan Dong Accreditation Center for Environmental \\ Impact Assessment, Jinan 250353, China. \\ alyfighting222@163.com, bspgc@163.com, eia001@126.com
}

Keywords: aniline, aerobic activated sludge, plant

\begin{abstract}
The enhanced degradation of refractory organic compounds by assisting plant during the activated sludge process has been a hotspot. Aniline was used as a model compound to study the reinforcement degradation of alocasia macrorrhiza during the activated sludge process. With the help of the assisting plant, the removal ratio of aniline could increase from $70 \%$ to $97.8 \%$ with reaction time 25hr, MLSS $3500 \mathrm{mg} / \mathrm{L}$. three main factors including MLSS, reaction time and initial concentration of aniline were studied by using single factor analysis method and orthogonal experiment. The suitable condition was selected on the basis of the aniline removal capability. According to the result of range analysis, the sequence for the three factors was reaction time $>$ MLSS > initial concentration. The optimal condition was MLSS 3500 mg/L, Initial concentration $30 \mathrm{mg} / \mathrm{L}$ and reaction time $14 \mathrm{hr}$, respectively.
\end{abstract}

\section{Introduction}

Aniline was an important industrial chemical used primarily in printing and dyeing, plastics, paints, pesticides and pharmaceutical industry. Aniline was hazardous to aquatic lives, damaging their central nervous system, cardiovascular system, liver and kidney ${ }^{[1]}$. It has been listed as one of the 129 priority pollutants by U.S. Environmental Protection Agency ${ }^{[2]}$. In China, aniline has been included in the 'blacklist of environmental priority pollutants ${ }^{\text {,3] }}$. Several technologies such as composite adsorbent, photocatalysis, reverse osmosis, catalytic wet air oxidation, electro catalytic oxidation, ferrate, aerobic cometabolism and ultrasonic degradation were used to treat aniline-containing wastewaters.

In many studies, plants were proved to absorb the pollutants from the soil-water systems. The pollutants, absorbed by plants, would be converted into the plants' nutrients, or evaporated into the atmosphere by transpiration ${ }^{[4]}$. In this paper, the enhanced degradation of aniline by the combination of plant and activated sludge was studied and the optimum conditions were discussed.

\section{Materials and methods}

\subsection{Chemicals}

All chemicals used in the experiment were of analytical or reagent grades. Anhydrous methanol (Tianjin Kemiou Chemical Reagent Co. Ltd, chromato- graphically pure), Aniline standard (National Institutes for Food and Drug Control), Activated sludge (Jinan Everbright Water ).

The alocasia macrorrhiza with the similar size and similar weight were chosen as the assisted plant. All they were 6 months old. 


\subsection{Analysis}

Aniline in aqueous solutions was analyzed with a high performance liquid chromatography (Shimadzu LC-20), which was equipped with a ultraviolet detector (SPD-M20A). The wavelength was set at $280 \mathrm{~nm}$. The column used was a reversed-phase C18 column $(5 \mathrm{~mm} \times 250 \mathrm{~mm})$. The mobile phase was a mixture of methanol and water $(50: 50, \mathrm{~V}: \mathrm{V})$ and its flowrate was set at 1.0 $\mathrm{mL} / \mathrm{min}$.

\subsection{Experiment}

\subsubsection{Sludge acclimation process}

The sludge was acclimated as follows. A certain amount of active sludge was aerated continuously in the experimental barrel. The mixed liquor suspended solids (MLSS) was maintained at 2500-3500 mg/L. The activated sludge was kept in a high activity by adding nutrients.

\subsubsection{Preparation of samples}

In order to destroy the protein in the supernatant, $10 \mathrm{ml}$ supernatant was mixed with $5 \mathrm{ml}$ methanol in an Erlenmeyer flask. The mixture was shaken for $10 \mathrm{~min}$ and filtered by a $0.22 \mu \mathrm{m}$ microfiltration membrane. The filtrate was analyzed by liquid chromatography mass spectrometry technology to determine the degradation process of aniline.

\section{Results and discussion}

\subsection{Sludge acclimation}

Table.1 Removal rate of aniline during the sludge acclimation process

\begin{tabular}{cccccc}
\hline $\begin{array}{c}\text { Initial concentration } \\
(\mathrm{mg} / \mathrm{L})\end{array}$ & 20 & 40 & 60 & 80 & 100 \\
\hline Time(d) & 3 & 4 & 5 & 5 & 7 \\
\hline $\begin{array}{c}\text { Final concentration } \\
(\mathrm{mg} / \mathrm{L})\end{array}$ & 1.848 & 3.348 & 4.573 & 6.625 & 27.16 \\
\hline Removal rate (\%) & 90.76 & 91.63 & 92.38 & 91.72 & 72.84 \\
\hline
\end{tabular}

Aniline was a kind of hazardous material to the microorganisms, making microorganisms inactive or even dead. The active sludge must be acclimated before they were used to treat aniline wastewater. Table 1 showed the effect of aniline concentration and acclimation time on the removal rate of aniline with MLSS $5000 \mathrm{mg} / \mathrm{L}$. If the concentration was lower than $80 \mathrm{mg} / \mathrm{L}$, more than $90 \%$ aniline could be removed during the period of 3-5 days. If the concentration was more than $80 \mathrm{mg} / \mathrm{L}$, the removal rate decreased sharply and could hardly be improved after extension of acclimation time. It could be seen that sludge acclimation could provide a good method to degrade aniline wastewater with low concentration.

\subsection{Reinforcement of (Auxiliary) assisted plant on the degradation of aniline}

The acclimated sludge was used to degrade aniline wastewater with aniline concentration of $20 \mathrm{mg} / \mathrm{L}$. Fig.1. showed the enhancement of plant on aniline degradation under the condition of MLSS $3500 \mathrm{mg} / \mathrm{L}$. If the reaction time was set $25 \mathrm{hr}$, the removal ratio reached $97.8 \%$ with the help of assisted plant, while it only reached $70 \%$ without plant. The removal ratio increased $37.9 \%$. It could be seen that under the help of assisted plant, high removal ratio could be obtained with short reaction time. 


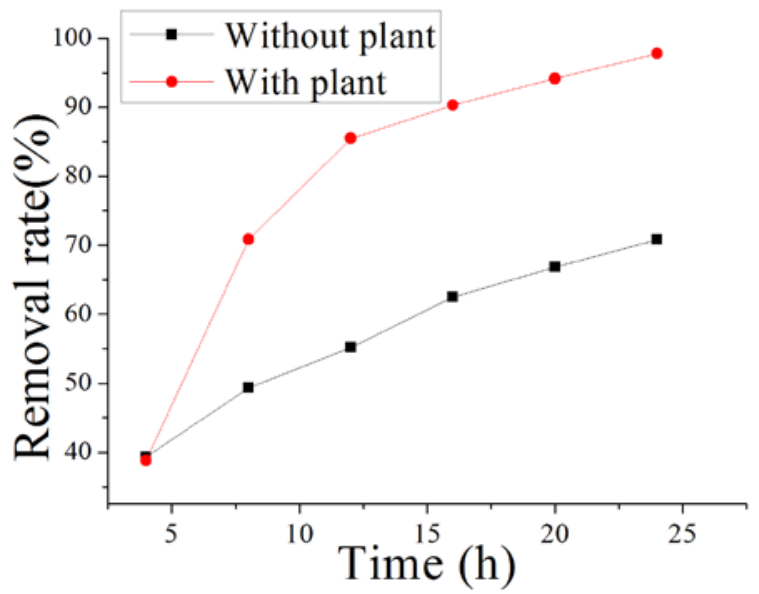

Fig.1. Reinforcement of assisted plant on the degradation of aniline

\subsection{Effect of mixed liquor suspended solids}

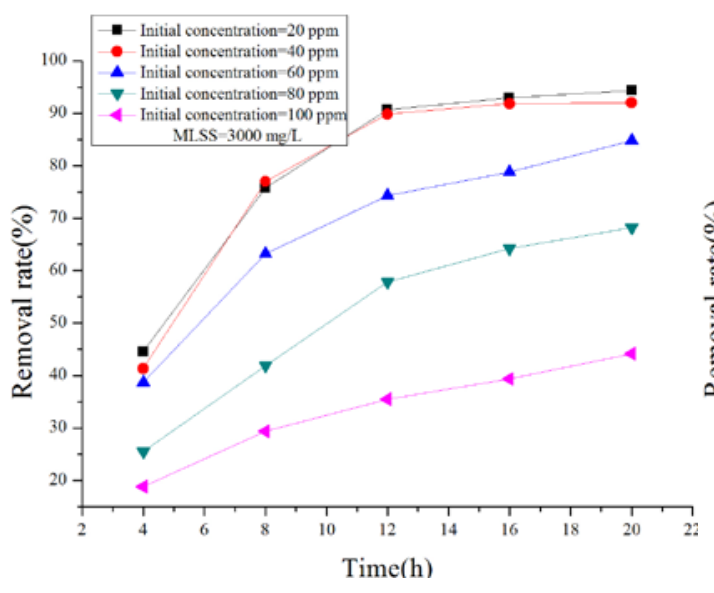

Fig.2.Effect of MLSS on the removal rate of aniline MLSS

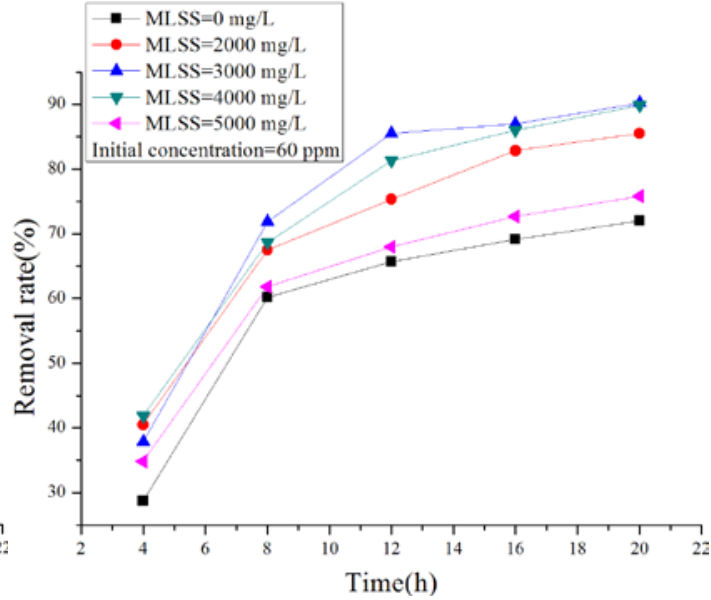

Fig.3. Effect of initial concentration of aniline on its removal rate

The effect of the sludge concentration on the removal rate could be seen in Fig.2. It could be seen that MLSS had a significant effect on the removal of aniline. The highest removal rate was obtained when the MLSS was $3000 \mathrm{mg} / \mathrm{L}$. The removal rate increased rapidly as the reaction time increased. If the reaction time was more than $12 \mathrm{hr}$, the increasement of removal ratio was not obvious. The suitable reaction was determined to be $12 \mathrm{hr}$.

\subsection{Effect of initial concentration}

Fig.3 illustrated the degradation of aniline under different initial concentration of aniline when the MLSS was $3000 \mathrm{mg} / \mathrm{L}$ in each barrel with plant. As can be seen from Fig.2 the maximum aniline degradation occurred and reached $92 \%$ and $91 \%$, respectivly, when the initial concentration was $20 \mathrm{mg} / \mathrm{L}$ and $40 \mathrm{mg} / \mathrm{L}$. The higher was the initial concentration, the lower the degradation ratio was. The possible explanation was that the high concentrations of aniline could have damaging effects on plants. If the initial concentration of aniline was lower than $40 \mathrm{mg} / \mathrm{L}$, there was no adverse affect on the activity of the active sludge. 


\subsection{Orthogonal test to determine the optimal experiment plan}

Table.2 Factors and level of orthogonal test L9 $\left(3^{3}\right)$

\begin{tabular}{cccc}
\hline & \multicolumn{3}{c}{ Factors } \\
\cline { 2 - 4 } Level & $\mathrm{A}$ & $\mathrm{B}$ & $\mathrm{C}$ \\
\cline { 2 - 4 } 1 & MLSS (mg/L) & Initial concentration (mg/L) & Time (h) \\
2 & 2500 & 30 & 10 \\
3 & 3000 & 40 & 12 \\
& 3500 & 50 & 14 \\
\hline
\end{tabular}

Orthogonal test was designed to determine the optimal experimental condition (Table.2).

Three factors such as MLSS, Initial concentration and reaction time were chosen and each factor was set three levels. According to the result of range analysis, it clearly showed, in Table.3, that the optimal combination of the three factors was A3B1C3. The sequence for the three influencing factor was $\mathrm{C}>\mathrm{A}>\mathrm{B}$. Reaction time was the most important factor and the initial concentration of aniline had the least effect.

Table.3 Result and differential analysis of orthogonal test $\mathrm{L}_{9}\left(3^{3}\right)$

\begin{tabular}{|c|c|c|c|c|}
\hline \multirow[t]{2}{*}{ Number } & A & $\mathrm{B}$ & $\mathrm{C}$ & \multirow{2}{*}{$\begin{array}{c}\text { Removal } \\
\text { rate(\%) }\end{array}$} \\
\hline & MLSS (mg/L) & Initial concentration (mg/L) & Time (h) & \\
\hline 1 & 1 & 1 & 1 & 70.83 \\
\hline 2 & 1 & 2 & 2 & 77.25 \\
\hline 3 & 1 & 3 & 3 & 87.00 \\
\hline 4 & 2 & 1 & 2 & 82.67 \\
\hline 5 & 2 & 2 & 3 & 88.75 \\
\hline 6 & 2 & 3 & 1 & 68.50 \\
\hline 7 & 3 & 1 & 3 & 86.83 \\
\hline 8 & 3 & 2 & 1 & 72.25 \\
\hline 9 & 3 & 3 & 2 & 84.20 \\
\hline $\mathrm{k}_{1}$ & 78.36 & 80.11 & 70.53 & \\
\hline $\mathrm{k}_{2}$ & 79.97 & 79.42 & 81.37 & \\
\hline $\mathrm{k}_{3}$ & 81.09 & 79.90 & 87.53 & \\
\hline $\mathrm{R}$ & 2.73 & 0.69 & 17 & \\
\hline $\begin{array}{l}\text { Good } \\
\text { level }\end{array}$ & A3 & B1 & C3 & \\
\hline \multicolumn{2}{|c|}{ Affect the order } & $C>A>B$ & & \\
\hline
\end{tabular}

\section{Conclusions}

The assisting plant, Alocasia macrorrhiza, was used to enhance degradation of aniline during the activated sludge. The removal ratio of aniline could increase from 70 to $97.8 \%$ with the help of assist plant when the reaction condition was set reaction time 25hr, MLSS $3500 \mathrm{mg} / \mathrm{L}$. three factors such as MLSS, reaction time and initial concentration of aniline were studied by the single factor analysis to select the optimal condition. The optimum conditions were set as follows, MLSS $3000 \mathrm{mg} / \mathrm{L}$, reaction time $12 \mathrm{hr}$ and initial concentration 20-40 mg/L. An orthorgonal test of L9 $\left(3^{3}\right)$ was carried out according to the result of single factor experiments. The sequence for the three factors was reaction time $>$ MLSS > initial concentration. The optimal condition was MLSS 
$3500 \mathrm{mg} / \mathrm{L}$, Initial concentration $30 \mathrm{mg} / \mathrm{L}$ and reaction time 14hr, respectively.

\section{References}

[1] Ye Z L, Sun X, Zheng L, et al. Study on degradation mechanism of aniline solution by potassium ferrate. Environmental Pollution and Control. Vol.31. (2009) No.4,p1 - 4.

[2] Li J, Xie C J. Study on aerobic co-metabolism biodegradation of aniline in wastewater. Chinese Journal of Environmental Engineering. Vol.1 (2007) No.6, p51 - 55.

[3] Zhang X, Dong X Q, Zhang M H, et al. Catalytic supercritical water oxidation of aniline.

Chemical Industry and Engineering Progress. Vol.26 (2007) No.3, p 413 - 416.

[4] Huang W J, Li Q X, Xie Y J, et al. Comparative study on the ability which utilized hydrophytes purify polluted water of river. Guihaia. Vol.34 (2014) No.5, p 642-650. 